\title{
0 encontro intergeracional entre crianças e idosos como espaço de construção de cidadania na infância
}

\author{
The intergenerational meeting between children and the elderly as a context of building \\ citizenship in childhood
}

\section{El encuentro intergeneracional entre niños y ancianos como contexto de construcción de ciudadanía en la infancia}

\author{
Ivone Maria Mendes Silva* \\ Simone Cristina Dalbello da Silva*
}

\section{Resumo}

Este trabalho apresenta reflexões sobre como a educação das novas gerações para a participação cidadã na vida social pode ser fomentada por projetos promotores de encontros intergeracionais entre crianças e idosos. Como aporte teórico do trabalho são encapadas contribuições de autores/as que abordam as interconexões entre infância, cidadania e educação, como Hannah Arendt e Manuel Jacinto Sarmento. O desenho metodológico do estudo incluiu a realização de pesquisa etnográfica, com uso de observação participante e recolhimento de narrativas produzidas por crianças e idosos ao longo de sua participação no projeto "Idosos Mestres da Vida", desenvolvido em escolas públicas de Concórdia-SC. Foi possível observar que o projeto funcionou como um espaço de coeducação, ao possibilitar a ampliação do horizonte de experiências e conhecimentos dos sujeitos participantes. Conclui-se que o convite feito às crianças para que identificassem relações entre presente e passado histórico instigou-as a produzirem reflexões sobre os processos que afetam a organização da vida social na atualidade e em outros tempos, bem como seus sentidos e implicações. O fomento dessa capacidade de leitura crítica da realidade representa um vetor fundamental para a constituição de sujeitos cidadãos plenos, capazes de se responsabilizarem não apenas pela cidadania individual, mas também comunitária e social.

Palavras-chave: Infância. Velhice. Cidadania. Intergeracionalidade. Coeducação.

Recebido em 15/10/2019 - Aprovado em 27/12/2019

http://dx.doi.org/10.5335/rep.v27i2.11427

Doutora em Ciências (área: Psicologia) pela Universidade de São Paulo/USP. Professora adjunta na Universidade Federal da Fronteira Sul (UFFS), Campus Erechim/RS, Brasil. Orcid: https://orcid.org/0000-0002-0058-091X. E-mail: ivone@ uffs.edu.br

** Mestra em Ciências Humanas no PPG da UFFS/Erechim/RS. Assistente social do Núcleo de Apoio à Saúde da Família (NASF) da Secretaria Municipal de Saúde de Concórdia/SC, Brasil. Orcid: https://orcid.org/0000-0001-9001-2969. E-mail: simonecdalbello@gmail.com 


\section{Resumen}

Este artículo presenta reflexiones sobre cómo la educación de las nuevas generaciones para la participación ciudadana en la vida social puede fomentarse mediante proyectos que promuevan encuentros intergeneracionales entre niños y ancianos. Como aporte teórico del trabajo están los aportes de autores que abordan las interconexiones entre infancia, ciudadanía y educación, como Hannah Arendt y Manuel Jacinto Sarmento. El diseño metodológico del estudio se centra en la realización de investigaciones etnográficas, junto con el proyecto intergeneracional "Ancianos Maestros de la Vida", desarrollado en las escuelas públicas de Concordia/SC. Se pudo observar que el proyecto funcionaba como un espacio de coeducación espacios de coeducación permitiendo la expansión del horizonte de experiencias de niños y ancianos. Se descubrió que la práctica de hacer comparaciones y relaciones entre el presente y el pasado histórico ha brindado a los niños la posibilidad de producir reflexiones sobre los cambios sociales que han afectado la organización de la vida social en el presente y otros tiempos, así como los sentidos y implicaciones de estos cambios, un proceso que representa un vector fundamental para la constitución de sujetos ciudadanos plenos, capaces de ser responsables no solo de la ciudadanía individual, sino también comunitaria y social.

Palavras clave: Infancia. Vejez. Ciudadania. Intergeneracionalidad. Coeducación.

\section{Abstract}

This paper presents reflections on how the education of new generations for citizen participation in social life can be fostered by projects that promote intergenerational encounters between children and the elderly. As a theoretical contribution of the work, contributions from authors addressing the interconnections between childhood, citizenship and education, such as Hannah Arendt and Manuel Sarmento. The methodological design of the study focused on conducting ethnographic research, in the "Elderly Masters of Life" project, developed in public schools in Concordia/SC, It was possible to observe that the project functioned as a co-education space, enabling the expansion of the horizon of experiences of children and the elderly. It was found that the practice of making comparisons and relationships between the present and the historical past gave children the opportunity to reflect on societal changes that have affected the organization of social life in the present and other times, as well as the senses and implications of these changes, a process that represents a fundamental vector for the constitution of subjects full citizens, capable of being responsible not only for individual citizenship, but also community and social.

Keywords: Childhood. Old age. Citizenship. Intergenerationality. Co-education.

\section{Introdução}

O presente trabalho apresenta reflexões sobre como a educação das novas gerações para a participação cidadã na vida social pode ser fomentada por projetos promotores de encontros intergeracionais entre crianças e idosos.

Consideramos que as práticas de coeducação construídas entre crianças e idosos, os quais têm seus processos de subjetivação e socialização marcados por contextos históricos distintos, podem exercer um impacto profundo sobre a forma como esses sujeitos se constroem como indivíduos e cidadãos. A coeducação de gerações, como lembra Oliveira (1998), supõe que crianças e idosos, ao conviverem, possam influenciar-se reciprocamente, alcançando aprendizagens múltiplas e se desenvol- 
vendo como pessoas por meio do intercâmbio de saberes, desde que as relações das quais participem sejam de fato igualitárias e as diferenças respeitadas. Nesse sentido, a coeducação de gerações tem sua importância afirmada como instrumento de desconstrução de preconceitos e visões estereotipadas sobre infância(s) e velhice(s), podendo ainda representar um caminho para a superação da indiferença ou intolerância em relação à alteridade.

O conceito de alteridade é aqui referido em sua estreita relação com o de cidadania, tomando por base o pensamento de Hannah Arendt, que fundamentará a discussão feita sobre a educação como dimensão estruturante da cidadania e o papel dos adultos face às crianças nesse processo.

A concepção de infância da qual partimos baseia-se, principalmente, nos escritos de Manuel Jacinto Sarmento (2002, 2004, 2005), que defende a superação do conceito de infância atrelado apenas a critérios etários e variáveis psicológicas e biológicas. Ele propõe que concebamos a infância como uma "categoria social do tipo geracional por meio da qual se revelam as possibilidades e os constrangimentos da estrutura social" (SARMENTO, 2005, p. 363). Ou seja, ao estudarmos a infância precisamos considerar o contexto social mais amplo com o qual se relacionam os "itinerários individuais de cada criança", pois eles só "fazem sentido se perspectivados à luz das condições estruturais que condicionam cada existência humana" (SARMENTO, 2002, p. 268). O que nos leva, sob essa perspectiva, a ressaltar a necessidade de considerar a infância no plural (infâncias), em função de não serem uniformes ou homogêneos os processos vividos pelas crianças enquanto sujeitos sociais. Adotamos também o plural ao nos referirmos à velhice, por admitirmos que são diversas as formas pelas quais pode ser significada e vivida essa etapa do ciclo da vida (MESSY, 1999).

Considerando as formas de participação social e de consolidação de práticas cidadãs disponíveis às crianças na atualidade, o alcance de avanços nesse âmbito, sejam eles promovidos pela ação do Estado na viabilização de políticas públicas seja pela atuação da sociedade civil organizada, constitui necessidade social das mais prementes, assim como o fortalecimento da interação comunitária, incluindo as mais diversas gerações.

Outro grande desafio a ser enfrentado por nossa sociedade na atualidade é a problematização e superação de visões estereotipadas e excludentes sobre infância(s) e velhice(s), as quais acabam impondo delimitações participativas e restrições no exercício da cidadania plena pelas crianças e pelos idosos. Talvez, um primeiro passo nessa direção seja, justamente, compreender tais visões como cons- 
truções sociais e não realidades fixas e acabadas, o que implica a possibilidade de serem mudadas.

Diante desse cenário, o tema da intergeracionalidade, considerando-se especialmente suas relações com a infância e a educação, suscita debates de grande relevância para o mundo acadêmico e para a sociedade mais ampla. Inserindo-nos nesse âmbito de estudos, essencialmente multidisciplinar, produzimos a discussão apresentada ao longo do presente artigo, que foi desenvolvida com base nas contribuições teórico-conceituais advindas dos autores supracitados e de outras fontes teóricas, em articulação com a análise de narrativas produzidas por crianças e idosos participantes do projeto "Idosos Mestres da Vida", realizado em escolas públicas da cidade de Concórdia/SC. Para tanto, foi utilizado o método etnográfico, baseado na observação participante dos encontros ocorridos como parte do projeto e a análise das narrativas construídas a partir da interação entre as crianças e os idosos. O cerne da proposta consistiu na apresentação, pelos idosos, de suas memórias autobiográficas e de conhecimentos acerca da história e cultura locais, seguida da troca de ideias e experiências com as crianças.

Nas próximas seções, as discussões anteriormente anunciadas serão desenvolvidas, com o artigo estruturando-se da seguinte maneira: a primeira seção traz considerações teórico-conceituais sobre coeducação de gerações, cidadania e infância. A segunda seção expõe o percurso metodológico da pesquisa, seguida da apresentação e discussão dos resultados obtidos. Por fim, são formuladas algumas considerações finais.

\section{Coeducação de gerações, cidadania e infância: o lugar das relações intergeracionais na educação das novas gerações}

Ao longo da história, as sociedades frequentemente têm delimitado seus grupos sociais por fronteiras de idade, mas é na Modernidade que esse processo ganha contornos mais nítidos em função da padronização das etapas da vida, da infância à velhice (DEBERT, 1998, 2010).

Em nossa sociedade atual, os diferentes grupos etários desenvolvem suas próprias culturas em espaços socio-ocupacionais específicos e há, em geral, pouco convívio viabilizador de práticas coeducativas com outras gerações, acentuando ainda mais essa fragmentação cronológica. Somado a isso, assiste-se hoje a uma grande valorização das tecnologias, as quais têm produzido grandes modificações nas rela- 
ções interpessoais. Não por acaso, a intergeracionalidade, e, mais especificamente, a coeducação de gerações, tem sido, muitas vezes, significada como algo difícil de ser alcançado no contexto contemporâneo, no qual idosos frequentam grupos de idosos e crianças ocupam-se das escolas. Tais situações acabam por segmentar as gerações e os próprios espaços socio-ocupacionais (SILVA; JUNQUEIRA, 2013), com repercussões negativas em vários planos.

Não obstante, como sustenta Debert (2010, p. 51), podemos considerar que "as etapas em que a vida se desdobra são relacionais e performáticas", o que implica que processos como a segmentação atualmente existente entre diferentes gerações possam ser colocados em questão e ressignificados. Até porque o convívio entre as diversas gerações e o processo de transmissão sociocultural por ele oportunizado são imprescindíveis a qualquer sociedade, sendo inviável concebermos a construção de um futuro pelas novas gerações sem que essas possam valer-se do legado e dos ensinamentos dos seus predecessores (BORGES; MAGALHÃES, 2011).

Assim, as relações intergeracionais estão diretamente implicadas na possibilidade de construção de processos educacionais que envolvam "todas as dimensões do ser humano: o singulus, o civis e o socius" (CURY, 2002, p. 254). Da mesma forma que "uma geração reúne alguns indivíduos, ela também produz distinções" (BORGES; MAGALHÃES, 2011, p. 174). Então, a prática intergeracional pode ser um "meio educacional" que estabelece um "processo de educação/aprendizagem bidirecional" (ANTUNES; MOREIRA, 2018, p. 22).

A educação é aqui reconhecida, portanto, como um caminho do qual cada indivíduo pode dispor como "chave de autoconstrução e de reconhecer-se como capaz de opções". E mais: como uma "oportunidade de crescimento cidadão" (CURY, 2002, p. 260). Isso porque somente quando efetivamos a educação como um processo de formação humana, processo para o qual as relações intergeracionais são fulcrais, é que criamos condições para que as crianças venham a desenvolver habilidades cognitivas e socioemocionais que, atreladas a uma capacidade de leitura crítica dos contextos sociais e existenciais nos quais se inserem, ampliam suas possibilidades de protagonizarem processos de participação social e até mesmo de transformação da realidade, por intermédio de práticas cidadãs. Nesse sentido cabe reconhecer que "a educação como direito e sua efetivação em práticas sociais se convertem em instrumentos de redução da desigualdade e das discriminações" (CURY, 2002, p. 261).

Nesse momento de nossa argumentação, a definição do que entendemos por cidadania e a explicitação de suas articulações mais profundas com a educação mostra-se fundamental. Com esse propósito em mente, recorremos às contribui- 
ções de Hannah Arendt, para quem a cidadania conjuga dois princípios centrais: por um lado, o princípio de alteridade, assentado no direito a ter direitos; por outro, nos projetos coletivos e na igualdade, facultada pelas leis que regem os interesses comuns. A autora convida-nos, portanto, a pensar a cidadania como uma construção que pode ser alcançada pelos indivíduos a partir da convivência coletiva e do pertencimento a uma comunidade política, na qual esses tenham seus direitos e liberdades fundamentais reconhecidos, assim como suas singularidades (ARENDT, 2010).

A expressão direito a ter direitos tem sido muito comentada como marca distintiva da definição dada pela autora ao conceito de cidadania. Essa discussão se faz presente não apenas em sua obra $A$ condição humana, citada anteriormente, mas também em As origens do totalitarismo. Dessa obra, é conhecida a passagem na qual Arendt anuncia que "o direito a ter direitos, ou o direito de cada indivíduo de pertencer à humanidade deveria ser garantido pela própria humanidade” (ARENDT, 1989, p. 332). Na sequência de sua argumentação, entretanto, a autora adverte que "nada nos assegura que isso seja possível", uma vez que a cidadania, como o próprio mundo de cultura na qual estamos imersos, é uma construção humana e, como tal, demanda a existência de certas condições para se tornar realidade. Tanto é que, na história recente, alguns sistemas totalitários (o Nazismo, por exemplo) nos confrontaram com a impossibilidade de exercício da cidadania. Como bem sintetiza Sawaia (1994), partindo das contribuições de Arendt:

Cidadania é consciência dos direitos iguais, mas esta consciência não se compõe apenas do conhecimento da legislação e do acesso à justiça. Ela exige o sentir-se igual aos outros, com os mesmos direitos iguais. Há uma necessidade subjetiva para suscitar a adesão, a mobilização, tanto quanto condições para agir em defesa destes direitos (SAWAIA, 1994, p. 152, grifos da autora).

E a formação dessa consciência, que tem como substrato principal a ética, requer a mediação do outro, ou seja, a possibilidade de integrarmos uma comunidade política que seja fonte de direitos e ao mesmo tempo nos eduque a praticar nossos deveres. Uma comunidade que nos ensine que "o parâmetro ético da liberdade é a alteridade, porque esta traz consigo valores como autonomia e responsabilidade [...]", dado que "o princípio fundamental da cidadania colocado pela modernidade contemporânea é o direito de viver a própria vida, ser único e diferente dos demais, enquanto igual a todos" (SAWAIA, 1994, p. 154-155).

A integração a comunidades plurais se efetiva, na vida cotidiana, via participação em contextos diversos, como família, escola, partidos, grupos de amigos e 
pares, associações de bairro etc., a partir dos quais passamos, desde a infância, a ter acesso ao "espaço público", aprendendo a cultivar a responsabilidade pelo bem comum ao fazer um uso consciente da própria liberdade. Ainda segundo Arendt (2005), o exercício dessa responsabilidade para com o mundo (também referida como amor pelo mundo) deve ser praticada pelos adultos e ensinada às crianças, constituindo um princípio fundante da cidadania, como a própria educação o é.

A educação é o ponto em que decidimos se amamos o mundo o bastante para assumirmos a responsabilidade por ele e, com tal gesto, salvá-lo da ruína que seria inevitável se não fosse a renovação e a vinda dos novos e jovens. A educação é, também, onde decidimos se amamos nossas crianças o bastante para não expulsá-las de nosso mundo e abandoná-las a seus próprios recursos, e tampouco arrancar de suas mãos a oportunidade de empreender alguma coisa nova e imprevista para nós, preparando-as em vez disso com antecedência para renovar um mundo comum (ARENDT, 2005, p. 247).

Educar as crianças implica, portanto, suscitar nelas o desejo de fazer parte desse mundo e de cuidar dele para que continue existindo. Para além disso, seria tornar-se responsável por "introduzi-las" nesse mundo, levando-as a compreender as relações, instituições e leis que dele fazem parte, bem como outras formas de legado deixadas pelas gerações anteriores. Trata-se, portanto, de assumir "[...] na educação a responsabilidade, ao mesmo tempo pela vida e desenvolvimento da criança e pela continuidade do mundo" (ARENDT, 2005, p. 235).

Apesar de Arendt (2005) destacar o papel dos pais humanos nesse processo, podemos admitir a existência de diversos atores sociais que podem assumi-lo, se imbuídos de uma intencionalidade educativa ancorada na responsabilidade pelo mundo e pelas próprias crianças, incluindo aqueles que aqui destacamos: os idosos. Cabe lembrar, como bem colocado por Oliveira (1998), que os idosos são aqueles "nascidos em outro tempo", fato que lhes confere a "condição de portadores do passado no presente e, graças ao burilar da memória" podem oportunizar às crianças o acesso a uma "cultura banhada na história vivida" (OLIVEIRA, 1998, p. 262).

Mas, como pondera Arendt, as sociedades modernas ocidentais têm enfrentado muitos desafios na concretização da educação das novas gerações se considerados os princípios anteriormente aludidos. A seu ver, esse processo guarda relação com a chamada "crise na educação", instaurada a partir da segunda metade do século XX em vários países e, mais amplamente, com a chamada crise da Modernidade, que se alimenta das transformações culturais pelas quais passam as sociedades ocidentais na atualidade ${ }^{2}$ (ARENDT, 2005).

Concordamos com César e Duarte (2010) em sua interpretação do pensamento arendtiano, quando afirmam que: 
O aspecto para o qual Arendt chama a atenção em sua reflexão sobre a crise da educação contemporânea diz respeito ao fato de que as fronteiras entre adultos e crianças vêm se tornando cada vez mais tênues, problema que, por sua vez, põe em destaque a falta de responsabilidade e o despreparo dos adultos para introduzir os recém-chegados no mundo. Afinal, como proceder criteriosamente nessa introdução educacional ao mundo quando a velocidade das transformações desse mundo é de tal monta que ele permanece desconhecido e estranho mesmo para os adultos que nele habitam e que, portanto, deveriam conhecê-lo? (CESAR; DUARTE, 2010, p. 826).

Ao nos referirmos à educação das futuras gerações, devemos levar em consideração também as mudanças que atingem a forma como a própria infância tem sido compreendida e vivida desde o emergir da Modernidade. Os estudos precursores de Philippe Ariès $(1981)^{3}$ sobre a infância como categoria social construída historicamente nos apontam que aquilo que se pensa, o que se espera e o que se pratica em relação às crianças variou muito ao longo da história. A concepção atual de uma infância dotada de particularidades, direitos, fragilidades e inocências nem sempre existiu. $\mathrm{O}$ que era comum para as crianças de outros tempos pode hoje ser considerado inadequado, ilegal e até desumano.

Partindo das considerações elaboradas por Áriès e outros autores que discutem a construção social da infância, Manuel Jacinto Sarmento (2004) afirma que várias mudanças ocorridas nas sociedades ocidentais ao longo dos últimos séculos possibilitaram a produção de uma "infância global, no plano normativo" (SARMENTO, 2004, p. 4). Dentre as mudanças destacadas pelo autor como propiciadoras desse processo estão: o surgimento de instituições (escola) e de saberes (pediatria, psicologia, pedagogia) voltados especificamente às crianças; a transformação dos cuidados dispensados a elas no interior das famílias e a constituição de normas e de prescrições indicando como deveriam ser tratadas. Entretanto, reconhece o mesmo autor, tais processos não eliminam as "desigualdades inerentes à condição social, ao gênero, à etnia, ao local de nascimento e ao subgrupo etário a que cada criança pertence. Há várias infâncias dentro da infância global” (SARMENTO, 2004, p. 6). Nesse sentido, cabe assinalar a existência, na realidade social, de várias infâncias, ou seja, diferentes formas de se viver essa condição, a despeito do que apregoam os discursos e práticas normatizadores.

Em outra de suas obras, Sarmento (2002) já alertava para o fato de que, mais do que nunca, podemos falar de uma "crise social da infância", reforçada principalmente pela exclusão social. Isso porque, contemporaneamente, é na infância que se refletiriam as maiores repercussões das mazelas sociais, econômicas, étnicas e de classes da nossa sociedade (SARMENTO, 2002, p. 267). Se, por um lado, há um 
reconhecimento de que a criança é um sujeito de direitos; por outro, é impossível negar que vivenciamos fragilidades na consecução desses direitos, principalmente em função do contexto macroestrutural ao qual estamos submetidos. Assim, estabelece-se um paradoxo: a infância vista como "depositária da imagem de paz" e, ao mesmo tempo, carregando os "efeitos geracionais da exclusão social" (SARMENTO, 2002, p. 268-269). E esses efeitos incidem diretamente "na habilidade da criança para participar" da vida em sociedade, pois além de repercutirem subjetivamente, ainda afetam o desenvolvimento emocional, crítico e social (TOMÁS, 2013, p. 57).

Esse contexto macroestrutural acaba por dificultar processos de consolidação da cidadania na infância. Ao pensarmos na criança como sujeito de direitos - expressão que ganha força, no Brasil, na década de 1980 e 1990, a partir de legislações específicas e políticas públicas - estamos pensando em um novo conceito de infância. Ou seja, a criança passou a "ser considerada não só como objeto, mas também como sujeito, ator e cidadão" (MONTEIRO; CASTRO, 2008, p, 280). Mas tal concepção ainda não concedeu às crianças "uma condição plena de cidadão", pois disponibiliza-se acesso aos direitos sociais, principalmente o direito à educação, mas ainda se restringe ao usufruto dos direitos de participação e do exercício dos direitos políticos. Não obstante, a consolidação de práticas democráticas e cidadãs na infância deve incluir, necessariamente, a participação das crianças (MONTEIRO; CASTRO, 2008). Assim, para a efetiva "expressão dos direitos das crianças", a "participação política e da vida democrática" são de extrema importância (SARMENTO, 2002, p. 276). Em outras palavras, a participação é "um imperativo para concretizar a criança como sujeitos de direitos" (TOMÁS, 2013, p. 51).

Um expoente dessa prerrogativa deve se fazer sentir, segundo a perspectiva que sustentamos, na própria forma como as crianças são percebidas e incluídas nos estudos que se propõem a analisar suas realidades de vida e/ou as percepções que elas nutrem sobre essas realidades. Podemos compreender sua participação, nesse contexto, por uma ótica que privilegie realizar pesquisa "com" crianças e não "sobre" elas (OHLWEILER; FISCHER, 2013), ao considerá-las atores sociais plenos, capazes de produzir cultura, tendo em vista sua condição de sujeitos de direitos e de desejos. Com base nessa perspectiva, que confere importância às opiniões e visões de mundo das crianças e concede espaço para que elas possam manifestá-las, é que optamos por realizar uma pesquisa de cunho etnográfico com as crianças participantes do projeto intergeracional aqui focalizado. Assunto para o qual voltaremos nossa atenção na próxima seção. 


\section{Percurso metodológico: "cenário, atores e regras" da pesquisa}

Esta pesquisa, de cunho qualitativo, foi realizada durante o período de outubro de 2017, em cidade de médio porte do oeste catarinense ${ }^{4}$. Os dados foram obtidos por intermédio do método etnográfico, que acompanhou idosos e crianças durante a execução de um projeto intergeracional.

A pesquisa etnográfica exige, por parte do pesquisador, um movimento de olhar e de ouvir o outro, bem como a criação de um processo de interação com outros contextos socioculturais e, nesse caso, geracionais. Como Geertz (1989, p. 15), entendemos que o que define a etnografia é a prática da "descrição densa" da realidade estudada e dos sujeitos nela implicados, a partir da imersão do/a pesquisador/a nessa realidade, aliada à própria interpretação da descrição.

Inspirando-nos nas contribuições de Magnani (2009) sobre a prática da etnografia, adotamos os conceitos de "cenário", "atores" e "regras", por ele formulados. Eles são aqui usados para fazermos referência às dimensões às quais estivemos atentas durante o processo de pesquisa.

O cenário escolhido para a realização desta pesquisa de campo foram algumas escolas da rede municipal de ensino de uma cidade de médio porte, situada no oeste catarinense, por meio do projeto intitulado: "Idosos Mestres da Vida", idealizado pelo Conselho Municipal do Idoso da cidade de Concórdia/SC. Foram contempladas seis escolas; entretanto, dessas, acompanhamos cinco. O Projeto Mestres da Vida tem como objetivo o fortalecimento de vínculos entre as crianças e os idosos, o compartilhamento de saberes, de modo a proporcionar às crianças a percepção daquilo que era importante na época dos avós, incluindo as brincadeiras, o lazer, o trabalho, as tradições, os costumes e as experiências que marcaram a vida dos idosos. Conteúdos esses que foram apresentados às crianças por meio de histórias e de narrativas, as quais ofereceram subsídios para debates sobre assuntos da atualidade e reflexões acerca das mudanças que ocorreram ao longo dos anos.

O critério de inclusão das escolas para as apresentações do projeto foi a manifestação de anuência das próprias escolas, ou seja, o Conselho Municipal do Idoso divulgou o projeto, e as escolas que demonstraram interesse e disponibilidade de recebê-lo foram as responsáveis pelo agendamento da visita dos idosos.

Os atores são tanto os idosos que apresentaram suas histórias de vida quanto as crianças que estudavam no terceiro ano do ensino fundamental e interagiam com eles. 
A metodologia do projeto consistiu na apresentação de slides com fotos de tradições, costumes, vestuário com os quais os idosos tiveram contato, apresentando miniaturas de ferramentas e de objetos utilizados há 50 anos ou mais ${ }^{5}$. As apresentações duravam, em média, uma hora e trinta minutos; e as narrativas produzidas pelos idosos e pelas crianças foram desencadeadas pelo uso dessas fotos e miniaturas.

A etnografia aconteceu durante o ano de 2017. Para sua realização, foram utilizadas, como instrumentos de pesquisa, a observação participante dos encontros, acompanhada da produção de diários de campo, com registros que contemplaram as narrativas dos idosos e das crianças, bem como as percepções e impressões da pesquisadora sobre o contexto de pesquisa. Também foram realizados relatórios para registro de informações que se destacaram em cada encontro com os idosos, os quais foram, em alguns casos, enriquecidos com dados oriundos de conversas informais realizadas pela pesquisadora com os sujeitos de pesquisa.

Quanto aos cuidados éticos adotados durante a consecução da pesquisa, cabe afirmar que os idosos assinaram termo de consentimento livre e esclarecido para o uso de suas narrativas (gravadas e escritas) e de suas imagens. Além disso, foi registrada, em ata, durante reunião plenária do Conselho Municipal do Idoso de Concórdia, a autorização para a participação e acompanhamento do projeto "Idosos Mestres da Vida" e uso dos resultados dos encontros intergeracionais. A Secretaria de Educação do Município foi comunicada sobre a realização do projeto e a utilização dos dados obtidos ao longo deste na pesquisa aqui descrita, tendo concedido autorização para tanto. Também foi obtida autorização dos responsáveis/pais das crianças para que ocorresse sua participação no projeto e na pesquisa associada a esse.

Os nomes das escolas nas quais o projeto "Idosos Mestres da Vida" ocorreu foram preservados, assim como a identidade das crianças, aqui designadas por nomes fictícios: Júlia, Júlio, Felipe, Helena, Larissa, Eduarda, Lara, Sophia, Miguel, Amanda, Romeu, Juliana, João, Pedro, Ana, André, Igor, Leonardo, Sophia, Cíntia, Clarice, Luana, Cristina, Gabriel, Alexandre, Alice, Aline, Luiz, Artur, Joaquim, $\mathrm{Rosa}^{6}$. Os nomes dos idosos também não são revelados, sendo referidos na pesquisa por meio dos nomes fictícios sr. Apolo e sr. Aquiles ${ }^{7}$. As escolas acompanhadas etnograficamente, serão numeradas como cenário 1, 2, 3, 4 e 5, sendo aqui descritas aquelas que foram acompanhadas durante a execução do projeto. Além disso, optamos por não expor as fotos mencionadas na seção Resultados da pesquisa, como forma de preservar a identidade dos participantes. 
Para a análise dos dados obtidos por intermédio da etnografia, utilizamos princípios da análise de conteúdo segundo o método proposto por Laurence Bardin (2016). Então, estruturamos a análise de acordo com as escolas visitadas. Posteriormente realizamos a descrição das narrativas e, na sequência, a produção das inferências, buscando relacionar nossas interpretações com as discussões já existentes na literatura científica sobre o tema.

\section{Resultados da pesquisa}

Apresentaremos, a seguir, os relatos do diário de campo produzido durante a etnografia. Nesse momento, selecionamos as narrativas das crianças e idosos que mais se destacaram ao longo das interações ocorridas entre eles no contexto do projeto intergeracional.

\section{Cenário 1}

A turma do terceiro ano do ensino fundamental dessa escola era composta por treze alunos. A turma era bem empolgada, agitada e participativa. Assim, demos início à apresentação das fotos pelos idosos. No decorrer do processo, mostramos uma foto que continha rolos de fumo. O fumo fazia parte da economia da região do Alto Uruguai Catarinense. Sr. Aquiles e sr. Apolo perguntam: "O que é isso?", as respostas das crianças foram: "Churrasco"; "Carne", "Lenha". Quando os idosos contaram que eram rolos de fumo, as expressões foram de espanto: "Nossa!". Júlia então afirma: "Hoje as pessoas vendem plantas de maconha" (risos da turma). Os idosos abordam os riscos de fumar e usar drogas, Júlia então comenta: "Eu tenho religião, não vou fumar".

No decorrer da conversa que se travou, os idosos foram relatando suas experiências com riqueza de detalhes. Então, perguntam: "Alguém já viu rolo de fumo?", respostas: "Não", "Eu só vi maconha". Sr. Aquiles e sr. Apolo, espantados, perguntam quase que simultaneamente: "Vocês conhecem maconha?" a resposta das crianças foi unânime: "Sim". Júlio, empolgado pelo diálogo que se construía, comenta: "Meu primo anda sempre com maconha na mochila". Felipe, assustado com o comentário do amigo, lança uma cotovelada de leve em Júlio e adverte-o: "Não conta isso" (mais risos na sala).

Mostramos a foto de uma plantação de trigo, pertencente ao acervo da família do sr. Apolo. Os comentários das crianças foram: "Era muito trigo"; "Eu conheço 
trigo". Júlia, muito participativa, pergunta espantada: "As crianças trabalhavam também?". Sr. Apolo aponta para a foto e fala: "Sim, as crianças ajudavam nas tarefas e esse sou eu". As crianças perguntam quase que ao mesmo tempo: "Sério?". Algumas crianças comentam: "Que legal". Sr. Apolo conta que a mãe estava grávida nessa época em que a foto foi registrada, que o pai dele dizia que a cegonha iria trazer o bebê. Helena então pergunta: "O que é cegonha?". Larissa comenta: "Minha mãe fala dessa tal de cegonha", após o comentário indaga: "Você veio então da cegonha?".

Percebemos como as crianças estão atentas ao que acontece ao seu redor. Misturam, muitas vezes, a realidade com a fantasia. Ao mesmo tempo que brincam e demonstram certa ingenuidade diante de alguns tópicos da conversação, produzem reflexões e questionamentos face a outros. Sabem participar de um debate sobre o uso de drogas enquanto acreditam na cegonha.

Ao final da apresentação confeccionamos um brinquedo de botão com as crianças. Os idosos se misturam em meio às crianças e as ensinam a brincar, enquanto essas ficam fascinadas com o brinquedo, principalmente pelo fato de poderem criá-lo. Os comentários foram os mais diversos: "Eu tenho esse brinquedo em casa, mas é de LED", "Já estou craque nisso", "É como um Spinner".

$\mathrm{Na}$ atualidade, vivemos um enraizamento na cultura da tecnologia e do consumismo que nos permite comprar tudo pronto. Construir o próprio brinquedo gerou uma satisfação tão grande nas crianças que os idosos não conseguiram mais obter suas atenções para abordar a temática da violência que, no planejamento inicial, compunha a pauta da apresentação.

\section{Cenário 2}

A turma era composta de vinte alunos, turma bem quieta e atenta, talvez porque antes dos idosos iniciarem as falas com as crianças, o diretor da escola deu instruções sobre como deveria ser o comportamento das crianças, durante aquilo que ele denominou de "palestra". Após essa conversa prévia com o diretor, as crianças demoraram para criar vínculos e interagirem com os idosos, custando a participar da conversa. Não teceram muitos comentários, mas demonstraram estar atentas à apresentação e aos relatos dos idosos.

Mostramos a foto de dois objetos utilizados para cavalgar: o selim e a sela. Os idosos perguntam: "conhecem?". As crianças respondem, unanimemente: "sim". Os idosos explicam que o selim é uma antiga sela de cavalos para mulheres, pois elas 
não podiam se sentar com as pernas abertas. Assim, nos casamentos que eram realizados a cavalo, a noiva sentava de lado utilizando o selim, enquanto a sela era utilizada pelo homem. Os idosos discutem junto com a professora a questão de que, na época em que se usava o selim e a sela, a mulher não podia se comportar como o homem. Havia restrições e convenções sociais a serem seguidas que implicavam em limitações no que se refere ao exercício de direitos, à presença em determinados espaços e ocupações.

Conforme o vínculo foi se estreitando as crianças começaram a interagir. $\mathrm{Na}$ foto da família na colheita do trigo, sr. Apolo, que pertence a essa família mostra como eles "batiam" os trigos. Antes de existirem as trilhadeiras para descascar o trigo, eles o descascavam com um utensílio chamado de Manguá. Sr. Apolo então mostra a miniatura do manguá. As crianças perguntam se esse instrumento servia para brigar. Os idosos explicam que não e fazem os movimentos para mostrar como era feita a utilização do objeto.

As crianças demonstram curiosidade para saber o que os idosos ganhavam de presente na época em que eram crianças. Os idosos relatam que ganhavam presentes como enxadas e sapatos de borracha. Sr. Apolo lembra, então, de mostrar como eram feitas as lanternas para iluminar as casas, que eles chamam de Chiaretto. Os idosos contam que a utilizavam para iluminar o ambiente para fazer as tarefas da escola. As crianças comentam: "Nossa!", “Como fazia luz?". Sr. Aquiles explica que eles usavam querosene para fazê-la funcionar. Eduarda muda de assunto e pergunta: "Vocês comiam o que?". Os idosos explicam que arroz, feijão, mandioca, polenta e carne, sendo essa dividida entre toda a família. Os pedaços mais nobres eram destinados aos mais velhos e os demais pedaços, divididos entre os mais jovens.

Durante a conversa, percebemos que a noção de tempo para as crianças é diferente da noção de tempo para os adultos. Tudo no mundo infantil é muito intenso. $\mathrm{Na}$ foto em que aparecem duas meninas, sr. Apolo para, olha para a foto, suspira e aponta para uma das meninas e exclama: "Essa é minha esposa". Eduarda pergunta: "Quantos anos ela tem?", sr. Apolo responde :"71 anos" e Eduarda então exclama: "Nossa!", Lara ainda complementa: "é muito tempo, né?".

A noção de transformação e de modificação das paisagens urbanas também causa espanto nas crianças, pois apresenta-se para elas uma realidade que não reconhecem e cuja transformação não acompanharam, apenas conheceram tal qual se apresenta na contemporaneidade. Na exposição da foto de uma Romaria, denominada Filha de Maria, que acontecia na praça, no centro da cidade de Concórdia/ $\mathrm{SC}$, as crianças demonstram seu espanto: "Nossa!", "Como nossa praça era dife- 
rente". Sophia, com muita dúvida, não reconhece a paisagem e indaga: "É a nossa praça?".

Os idosos falaram dos castigos aplicados na época em que estudavam e os alunos começam a compartilhar experiências que os pais dividiram com eles. Miguel conta: "O meu pai falava que quando não obedecia na aula ele não podia voltar para escola durante uma semana e ainda apanhava em casa”. Sr. Apolo contou uma história de sua infância: sua mãe havia feito um calção para ele ir jogar bola utilizando o saco de farinha como tecido e, ao utilizá-lo, todas as crianças com quem costuma brincar riram dele. Intrigado, ele foi verificar o motivo e descobriu que todos riam porque atrás do calção estava escrito: "cinquenta quilos de farinha". Ao escutarem esse relato, as crianças participantes do projeto riem.

Como a cena descrita ilustra, os idosos faziam de tudo para serem atrativos para as crianças em suas interações para com elas. Deixaram claro que para eles era importante cativar a atenção e cumplicidade das crianças nesse momento de diálogo e troca de experiências. Além disso, demonstraram sentir orgulho de suas trajetórias, da idade que alcançaram e de terem construído uma história permeada por muito trabalho, dificuldade e luta.

Sr. Aquiles conversa com as crianças sobre violência e respeito para com os idosos, pede para as crianças visitarem seus avós, conversarem com eles, ouvirem suas histórias e não desapontarem seus familiares: "vocês são um pedaço deles". Amanda, que até então estava quieta, interage: "Todo dia eu vou na minha avó". Romeu conta-nos: "Meu avô levou uma garrafada na cabeça por causa de uma aposta de baralho e ficou cego". A visão de violência demonstrada pelos idosos, em suas falas, remete ao plano simbólico, quando passam a mensagem às crianças de que o desrespeito e a não valorização daqueles que amamos (expressas na falta de cuidado, atenção e diálogo) podem representar uma violência para com o outro. As crianças escutam e sentem liberdade para relatar outras formas de violência com as quais também têm contato, entre elas a violência física. $O$ diálogo se instaura.

\section{Cenário 3}

Nessa escola, foram reunidas três turmas: a do terceiro ano, quarto ano e quinto ano do ensino fundamental. As crianças, por meio de suas falas, expressaram certo conhecimento sobre a trajetória histórica da cidade e de sua própria genealogia, como demonstram os excertos de narrativas reproduzidos a seguir: 
"Minha avó veio da Suécia e teve 10 filhos", diz Juliana toda orgulhosa.

"Na época tinha a serra com dois lados, cada um pegava de um lado para serrar", comenta João, muito seguro de si, quando os idosos explicam sobre as primeiras serrarias.

"Na frente da praça, no museu, tem uma", conta Pedro, quando um dos idosos mostra a foto de uma Bruaca.

"No programa do Chaves tem uma máquina de foto dessa", observa Ana sobre a câmera fotográfica de alguns anos atrás.

"Meu tio faz isso ainda", relata André sobre o uso do Mangual para descascar os grãos.

"Tem o pilão também", comenta Igor, quando os idosos mostram um Monjolo.

"Eu vi isso, só que era maior", diz Leonardo sobre o uso no Monjolo para moer grãos.

"Minha bisavó tem um ferro de passar roupa igual a esse", compartilha Shopia, apontando para a foto projetada, que continha um paneleiro. No topo do paneleiro, havia um ferro de passar roupa, daqueles que necessitavam ser aquecidos no fogão.

"Eu tenho uma dessas para ir na catequese", explica Cíntia, em resposta à exposição feita pelos idosos de uma mochila que utilizavam para ir à escola na infância.

"Quando a minha mãe não fazia o tema a professora dava uma reguada na mão dela", afirma contundentemente Clarice ao compartilhar a experiência de sua mãe, quando conversamos sobre os costumes escolares vividos pelos idosos.

Todos esses exemplos demonstram o grande interesse por parte das crianças em relação aos detalhes das fotos e à discussão dos temas propostos pelos idosos. Esses, por sua vez, apresentaram grande habilidade para escutar as crianças e dialogar com elas, ao mesmo tempo em que lidavam com suas próprias memórias e sentimentos face ao passado, que os levaram, em alguns momentos, a tecer comparações saudosistas contemplando a realidade à qual tiveram acesso em suas juventudes e a realidade atual. Revelaram que o tempo histórico que marcou a forma como foram educados e algumas das tradições e visões de mundo que assimilaram é por eles reconhecido e valorizado até os dias de hoje, conforme expresso nas situações narradas a seguir:

Sr. Apolo comentando com as crianças sobre as serrarias da época expressa: "Levava meio dia para cortar uma árvore". Sr. Aquiles complementa: "Hoje em dia para qualquer pedacinho de lenha eles já utilizam a motosserra". 
Sr. Apolo mostra uma tramela e a chave que utilizavam. A tramela corresponde à fechadura utilizada nas portas de suas primeiras casas e a chave consistia em um pedaço de ferro. Luana, espantada, comenta: "Se alguém tivesse um ferrinho como esse podia abrir a porta?". Sr. Aquiles explica que "naquela época" ninguém pensava nisso e havia muito respeito com a propriedade alheia.

Os idosos contaram como era o namoro em suas juventudes, contextualizando a importância do casamento e de ter filhos. sr. Aquiles fala sobre se preparar para o casamento, conhecer bem o cônjuge, pois na época deles o casamento era para sempre. Laís comenta: "Meus avós disseram que os pais escolhiam o marido e a mulher para os filhos". sr. Aquiles comenta algumas diferenças com a atualidade, em que é cada vez mais comum os casais optarem por não terem filhos, sendo que os significados atribuídos ao namoro e ao casamento também mudaram.

Ao mostrar a foto de primeira comunhão, sr. Apolo fala a data que o evento aconteceu, afinal a foto se se refere a sua primeira comunhão: "Foi dia dois de fevereiro, há sessenta e três anos atrás, eu tinha sete anos na época". Gabriel pergunta: "Eram teus colegas esses na foto?". E o idoso responde: "Sim, eram todos meus colegas".

Por várias vezes os idosos mostravam a foto e conversavam sobre ela, ficando por segundos olhando para a mesma, antes de prosseguirem para o próximo slide, num momento em que se permitiam reviver o passado ali registrado pela foto. $\mathrm{E}$ as crianças, em geral, também se entregavam, por algum tempo, à contemplação, num ritmo pautado pela interação com os idosos, como durante as conversações.

Ao término do encontro, sr. Aquiles afirma. "Vocês são um pedacinho dos avós de vocês, pioneiros de Concórdia".

Ao final, todos batem palmas e uma menina abraça carinhosamente um dos idosos, num gesto vívido de afeto e gratidão, como se eles fossem de sua própria família. Muitas crianças se sentiram familiarizadas com os idosos e com suas histórias, principalmente por remeterem a seus avós e muitas tradições que marcaram seus antepassados e ainda são presentes em muitas famílias.

\section{Cenário 4}

A turma nessa escola era composta por vinte e quatro alunos. Alguns fatos nos chamaram a atenção durante a interação dos idosos com as crianças nesse dia. Uma delas foi a capacidade de recordação dos idosos. Sr. Apolo, ao apresentar a foto de uma serraria, fala o nome completo de todos os homens presentes na foto, como 
se esse fosse um fato ocorrido no dia anterior. Lembra-se dos detalhes quase como se ainda fizessem parte de sua realidade atual.

Seguindo as falas, sr. Apolo aponta para a foto de sua primeira comunhão e indica: "Esse sou eu". As crianças tecem muitos comentários: "Que fofo"; "Difícil saber"; "Novinho"; "Tu ainda se lembra dos teus colegas?". "Sim", responde sr. Apolo.

Os idosos mostram a mochila que utilizavam para levar seus materiais escolares e a professora da turma diz com muito entusiasmo: "Minha primeira mochila foi assim". Um dos idosos coloca a mochila em um dos meninos e as outras crianças riem. Alexandre, então, percebe um detalhe e diz: "Não dava para colocar o celular aí dentro". O fato da mochila não ter espaço para guardar o celular, objeto muito familiar para as crianças, causa espanto nelas. Esse comentário mostra como as crianças estavam presentes e abertas à interação, fazendo conexões entre as situações relatadas pelos idosos e a realidade atual vivida e observada por elas. Em outras palavras, estavam construindo seus próprios aprendizados a partir do diálogo com os idosos e da mediação das histórias contadas por eles.

Sr. Apolo chama a atenção da foto que está exposta no slide, dessa vez mostrando o corte de cabelo do menininho da foto explicando que os pais cortavam os cabelos das crianças em casa, pois não havia cabeleireiro ou barbeiro. Alice, então comenta: "A minha mãe corta o meu cabelo". Aline retruca: "Claro, ela é cabeleireira" (risos na sala). Luiz comenta: "Minha mãe cortou minha orelha uma vez". Sr. Aquiles conta que para combater a pediculose, seus pais utilizavam veneno. As crianças falam espantadas: "Meu Deus" e Alice complementa: "Minha mãe passa o pente". Nesse momento houve uma grande interação das crianças com os idosos, no qual aquelas comentam as experiências narradas por esses e as compararam com sua realidade.

\section{Cenário 5}

A turma era composta por dezenove alunos. Ao chegar na sala, arrumamos os materiais. A turma foi chegando aos poucos e os alunos foram se acomodando. Questionamos: "vocês sabem o que estamos fazendo aqui?". Algumas crianças respondem que sim, e então a proposta do projeto é apresentada. Nisso, Artur olha para os idosos e diz muito feliz, com um brilho no olhar conta: "Deixa eu contar para vocês do presente que o meu vô fez para mim. Ele demorou um ano para fazer esse presente: um carrinho de rolimã! Mas não é qualquer carrinho de rolimã, ele tem uma direção especial e freio!". 
No embalo, Joaquim conta: "Meu avô tem várias coisas antigas até uns rádios". Antônio também comenta: "Eu não sou de comprar brinquedos, eu gosto de fazer meus brinquedos". Antes mesmo dos idosos iniciarem suas narrativas, as crianças já estavam interagindo e compartilhando suas experiências.

Quando foi exposta a foto do churrasco realizado com espetos de madeira em comemoração a um aniversário de casamento, as crianças tecem os seguintes comentários: "Nossa Senhora"; "Eu já vi churrasco assim"; Luiz ressalta: "Antigamente a carne era bem mais barata". Sr. Aquiles explica que ele e sua família criavam os animais e depois abatiam para comer e diz que a carne era bem mais saudável, pois os animais pastavam e não eram alimentados com rações. Luiz retribui: "Acredito mesmo".

Uma conversa de iguais se estabeleceu naquele encontro, com as crianças trazendo os assuntos para a sua realidade, inclusive discutindo o preço da carne ou a questão da crise da economia, que nos exige uma tarefa de economizar em todos os aspectos. Como quando os idosos mostram a miniatura do Chiaretto, que era a lâmpada da época e precisava de querosene para funcionar. "Hoje a gente tem que economizar luz vocês tinham que economizar querosene", reflete Luiz.

A conversa estava tão fluída que os idosos contam detalhes do cotidiano das suas vidas de criança, como o fato de que as fraldas que utilizavam eram feitas de tecido, assim como os bicos (chupetas). As mães colocavam açúcar no pano para as crianças chuparem e se acalmarem. A professora comenta que as famílias que adquiriam açúcar eram consideradas ricas na época: "Só tinha açúcar quem criava porco e conseguia trocar por açúcar!".

Então, os idosos mostram a foto de uma família com doze filhos. Sr. Aquiles chama a atenção para as roupas, todas com a mesma estampa de tecido, pois os tecidos eram comprados em rolos nos armazéns e completa: "Para poder casar as mulheres tinham que saber costurar e cozinhar". Rosa, menina bem ativa, levanta o dedo e pede autorização para falar, cruza os braços e declama: "E o homem tinha que saber fazer o que? Já que a mulher tinha que saber costurar e cozinhar?". Sr. Aquiles explica que o homem tinha que ser trabalhador, saber trabalhar. As crianças todas levantam a mão para fazer perguntas, mas a professora intervém dizendo não há tempo para perguntas e pede para deixar os idosos prosseguirem com as apresentações.

Em todos os outros encontros com as crianças, a foto da família com vários filhos não gerou um debate feminista; nas outras escolas a foto gerou certo burburinho entre as crianças e uma curiosidade de saber o motivo dos casais terem muitos 
filhos, já que a realidade atual não diz respeito a famílias muitos extensas. Mas, essa menina, ao tecer esse comentário, surpreendeu até a professora, questionando a preparação das mulheres para o casamento em detrimento da preparação dos homens. Infelizmente, o debate em torno dessas questões não foi fomentado, como é possível depreender ao considerar a intervenção feita pela professora.

\section{Discussão}

Simone de Beauvoir (1990) explica que, em muitas sociedades, as crianças e os idosos, devido à sua incapacidade prática e liberados de certas pressões sociais, distanciam-se da seriedade dos adultos e brincam juntos, mantendo, assim, uma estreita relação. Isso, todavia, não tem sido algo comum de se observar como parte da realidade cotidiana da população em geral, nas sociedades modernas ocidentais. E os motivos são diversos, conforme analisamos inicialmente neste artigo.

Não obstante, quando crianças e idosos têm a oportunidade de resgatar e compartilhar histórias, dialogando a partir delas, possibilidades desconhecidas até então lhes são apresentadas. Os sujeitos participantes da presente pesquisa, por exemplo, entregaram-se a um movimento de reconhecimento reflexivo de suas realidades presentes a partir do resgate e da confrontação com o passado, permitindo a discussão de ideias, visões de mundo, práticas naturalizadas e processos sociais.

Foi possível notar que, nas interações estabelecidas entre as crianças e os idosos que participaram da pesquisa, a dominação de certos códigos culturais pelos idosos, e desconhecidos pelas crianças em função de pertencerem a uma geração distinta daqueles, não impediu que os processos comunicativos entre eles ocorressem de forma fluída. Um fator que pareceu pesar a esse favor foi o interesse mútuo no estabelecimento das interações, com disposição demonstrada pelas crianças para compartilhar opiniões e buscar esclarecimento através de perguntas, assim como o investimento feito pelos idosos na construção de um diálogo acolhedor das dúvidas e comentários das crianças.

Outro aspecto a ser comentado refere-se ao fato de que os idosos são oriundos de comunidades rurais que tem como principal fonte econômica o trabalho na agricultura e, das escolas que acompanhamos, apenas uma localizava-se no meio rural. Ainda assim, foi possível notar que as crianças demonstraram certa familiaridade com as histórias contadas pelo sr. Aquiles e sr. Apolo e em relação a algumas das expressões por eles referidas em suas narrativas, até em função do convívio com os próprios avós, oriundos, em sua maioria, de comunidades rurais. Com isso que- 
remos afirmar que as influências geracionais também se fazem sentir nas relações familiares. Há que se considerar ainda o fato de compartilharem com os idosos a mesma inserção socioeconômica e regional, sendo todos eles (crianças e idosos) oriundos das camadas populares e moradores da cidade de Concórdia/SC.

Cabe ainda, na contemplação dessa questão, lembrarmos o alerta feito por Sarmento (2005, p. 364) sobre o emprego do conceito de geração como "categoria social estruturante da infância" nas pesquisas sociológicas atuais, as quais não o tomam de modo isolado, mas sim buscando atentar para suas possíveis articulações com outros marcadores sociais, como as diferenças e desigualdades de classe, etnia/ raça, gênero etc. Nas palavras de Sarmento, esse cuidado no emprego do conceito é importante para que os/as pesquisadores/as não percam de vista os possíveis efeitos que esses marcadores, de forma isolada ou conjugada, podem exercer sobre os processos de estratificação social e sobre a construção dos indivíduos enquanto sujeitos sociais (SARMENTO, 2005).

Para além do fato de compartilharem certas características relacionadas à sua posição social, as crianças e os idosos que participaram do projeto tiveram suas interações, nesse contexto, marcadas pelo respeito mútuo. Tais interações, segundo nos parece, foram propiciadoras da formação de uma espécie de "corrente identificatória" (GOLDFARB; LOPES, 2018, p. 2188), percebida mediante análise das narrativas que demonstraram uma preocupação dos idosos com o porvir das crianças, com demonstração, inclusive, de certa carga afetiva. As crianças, por seu turno, corresponderam com perguntas sobre os idosos e suas famílias, buscando descobrir como estes haviam vivido suas infâncias e como eram quando crianças. Sinais de solidariedade e empatia foram emitidos várias vezes nas narrativas produzidas pelas crianças, nos cinco cenários analisados.

As formulações de Hannah Arendt (2005) sobre a relação entre educação e cidadania são pertinentes para analisarmos mais a fundo esse processo de construção de laços identificatórios entre as crianças e os idosos, em especial as ideias que a autora defende acerca do exercício da responsabilidade para com o mundo, a ser praticada pelos adultos e ensinada às crianças. Uma responsabilidade que, quando assumida de fato, se converte em atos que garantam que as futuras gerações recebam o legado cultivado por seus antecessores e queiram dar continuidade à (re)construção desse mundo e sua cultura, instituições, práticas etc. Esses dois idosos, sr. Aquiles e sr. Apolo, certamente demonstraram que o exercício dessa responsabilidade é possível e fecundo. E isso ocorreu não apenas ao se colocarem no papel de educadores dessas crianças - educadores no sentido lato do termo, ou seja, 
como aqueles que se propõem a ensinar, compartilhando saberes e experiências -, mas também por se dedicarem a fazê-lo de um modo democrático e inclusivo. O que pode ser observado nas cenas que ilustram as interações estabelecidas entre esses sujeitos, pontuadas, em geral, pela participação ativa das crianças na construção dos diálogos, com reconhecimento tácito, por parte dos idosos, de sua condição de produtoras de conhecimento.

Ao mesmo tempo que compartilharam suas narrativas com as crianças, transmitindo cultura e o valor de suas experiências pessoais, os idosos abriram espaço para que as crianças se comportassem como autoras de perguntas, comentários, divagações, reflexões e análises. E, por essa via, revelam explicitamente como a educação pode se constituir um princípio fundante da cidadania. Isso fica patente quando, na descrição do Cenário 5 por exemplo, nos deparamos com a análise da situação econômica do país feita por Luiz, que pondera sobre as implicações das restrições materiais vividas por sua família e também pelos idosos ("Hoje a gente tem que economizar luz vocês tinham que economizar querosene"). Vimos também a provocação feminista lançada por Rosa ("E o homem tinha que saber fazer o que? Já que a mulher tinha que saber costurar e cozinhar?”). Essas crianças estão pensando por si mesmas sobre o mundo e as variáveis sociais e econômicas que ditam possibilidades e limites às pessoas que dele participam; estão indagando sobre as diferenças e desigualdades existentes entre homens e mulheres no passado e no presente; estão dialogando sobre as mudanças em curso na contemporaneidade ("Como pode não haver espaço nessa mochila de antigamente para um celular?") e sobre processos que fazem parte de suas realidades existenciais ("Meu avô levou uma garrafada na cabeça", "Meu primo anda sempre com maconha na mochila").

Dessa forma, os encontros intergeracionais favoreceram a ampliação dos horizontes de experiências tanto dos idosos quanto das crianças, pois o diálogo com o outro dá acesso a conhecimentos e à possibilidade de ressignificar a própria percepção de realidade dos pares. Esse processo é nomeado por Tomás (2013) como "processos autônomos" de participação, nos quais as "crianças têm o poder de empreender a ação" e tornam-se sujeitos ativos do processo de ensinar e aprender (TOMÁS, 2013, p. 50).

As palavras de Bosi (1994), ao defender que não há como o ser humano saber o que ele é sem sair de suas determinações atuais, sintetizam a importância que encontros intergeracionais como os aqui analisados podem assumir na vida das crianças: 
Um mundo social que possui uma riqueza e uma diversidade que não conhecemos pode chegar-nos pela memória dos velhos. Momentos desse mundo perdido podem ser compreendidos por quem não os viveu e até humanizar o presente. A conversa evocativa de um velho é sempre uma experiência profunda: repassada de nostalgia, revolta, resignação pelo desfiguramento das paisagens caras, pela desaparição de entes amados, é semelhante a uma obra de arte (BOSI, 1994, p. 82).

Além das mudanças de valores apontadas pelos idosos na atualidade, a transformação das paisagens do território local também foram elementos destacados por eles nos encontros com as crianças, produzindo marcas na constituição identitária das crianças, uma vez que nossas identidades também são construídas pela relação com os espaços que habitamos e os significados atribuídos a eles. Ao mostrar, por exemplo, fotos da praça central da cidade, os idosos refletiram sobre como tudo está diferente do passado e as crianças pareceram não reconhecer, "nesse território, também ele envelhecido e modificado pelas transformações que lhe foram ocorrendo" (VEIGA; FERREIRA, CORDEIRO, 2016, p. 460), o que, até então, lhes parecia familiar: a mesma praça de sempre. Esse olhar diferenciado para o "de sempre" produz efeitos de estranhamento e reflexão sobre quem fomos, somos ou almejamos ser, a que sociedade pertencemos etc. Movimentos esses que podem ser, em diferentes níveis, favoráveis ao nosso desenvolvimento como pessoas e cidadãos, uma vez que produz reverberações em nosso senso de identidade pessoal e social, assim como na forma como vivemos nossos pertencimentos e lutas (VEIGA; FERREIRA; CORDEIRO, 2016).

A cidadania construída por meio da comunicação entre gerações permite um olhar integral sobre a vida humana e maneiras de conhecer e intervir na realidade local. Para que se amplie a visão de educação e se construa um entendimento da criança como um sujeito de direitos, há que se aliar o projeto pedagógico com práticas educativas que se pautem, também, num convívio promotor do diálogo de fato, para o desenvolvimento pleno de inúmeras aprendizagens pelas crianças, percebendo-as como protagonistas desse processo. E nesse ponto concordamos com Sarmento (2002), quando ele afirma que se a escola, enquanto "política da vida" e "utopia realizável", for capaz de assimilar essa lógica dos direitos da criança, ela poderá "reconstituir-se e refundar-se civicamente" (SARMENTO, 2002, p. 278).

\section{Considerações finais}

No projeto intergeracional aqui acompanhado, pudemos constatar que iniciativas no campo da coeducação de gerações podem favorecer a formação de sujeitos cidadãos. Os encontros ocorridos entre idosos e crianças, nas escolas em que essas estudam, propiciaram a ampliação dos horizontes de experiências de ambos. 
Ao terem a oportunidade de conversar com os idosos sobre temas de cunho econômico, social, educacional e familiar, as crianças puderam não apenas ter acesso a informações que passaram a fazer parte de seus repertórios culturais, como a exercitar o respeito à diferença (de opinião, de valores etc.). Esse processo fomentou a produção de questionamentos e ressignificações das visões que elas sustentam sobre o mundo e sobre as formas efetivas de nele intervirem em prol do bem comum, para além da afirmação dos interesses e necessidades individuais.

Em vista disso, concluímos que criar condições para formar sujeitos cidadãos implica, além da garantia de acesso a conhecimentos relativos a direitos e deveres, a possibilidade de conviver com o outro e aprender, consequentemente, que a sociedade é plural.

Além disso, conhecer e valorizar o passado permite que nossas crianças saibam quem são e no que podem se transformar. Favorecer um percurso escolar que valorize, por intermédio da intergeracionalidade, a cultura regional e que considere a pluralidade de tradições, media as aprendizagens necessárias para o desenvolvimento pleno das crianças e a construção de uma cidadania ativa, além da valorização social da velhice. É nesse compartilhamento de experiências de vida que as novas gerações conhecem o passado, apreendem o presente e projetam o futuro.

O exercício de pensar junto e ouvir o outro facilita momentos de construção e compartilhamento de saberes, se apresentando como uma arte: a arte de partilhar e de construir afeições e respeito mútuo e de construir espaços de consolidação da cidadania (BOSI, 1994). Todas essas dimensões são fundamentais para o desenvolvimento, pelas crianças, da capacidade de atuar política e socialmente no mundo do qual fazem parte.

\section{Notas}

1 Sarmento (2005) demarca a diferença conceitual entre infância e criança, ao afirmar que as crianças "são os actores sociais concretos que em cada momento integram a categoria geracional infância [...], sendo esta historicamente construída, a partir de um processo de longa duração que lhe atribuiu um estatuto social e que elaborou as bases ideológicas, normativas e referenciais do seu lugar na sociedade". Mas, conforme ressalta, o significado e lugar social atribuído à infância estão sempre sendo atualizados pelos atores sociais, sejam eles crianças ou adultos (SARMENTO, 2005, p. 363-365).

2 A obra Entre o passado e o futuro (ARENDT, 2005) foi escrita nas décadas de 50 e 60 (1954 a 1964) nos Estados Unidos, país no qual a autora vivia e cuja cultura é analisada por ela considerando as especificidades daquele momento histórico. Arendt discute, na obra em questão, aspectos referentes ao que identificou como "crise na educação", relacionando esse processo à chamada "crise de autoridade" (ARENDT, 2005). Ainda que teça suas considerações partindo da análise desse contexto (sociocultural e histórico) específico, a autora adverte que a chamada "crise na educação" deve ser considerada um fenômeno mais abrangente, cujas manifestações se fazem sentir em países diversos. Constatação que pode ser estendida também a 
outros momentos históricos, pois a análise de Arendt permanece atual e muito apropriada para problematizarmos cenas da vida contemporânea, como também entendem Ohlweiler e Fischer (2013).

3 A obra História social da infância e da família foi publicada pela primeira vez na França em 1960 e nos Estados Unidos em 1962.

4 A cidade de Concórdia, na qual realizamos a pesquisa, localiza-se na região oeste do Estado de Santa Catarina. Conforme estimativa do IBGE (2018), possui cerca de 74.106 habitantes. A colonização deu-se por gaúchos descendentes, principalmente, de italianos e alemães. No que diz respeito à economia, as atividades concentram-se na agroindústria e na agropecuária. O Índice de desenvolvimento humano municipal (IDHM) é de 0.800 .

5 As miniaturas dos objetos compreendem: uma miniatura de uma tramela (fechadura utilizada nas primeiras casas dos idosos); um chiareto, nome dado à lâmpada que era confeccionada com vidro e um tecido que era queimado com querosene; um monjolo, equipamento de madeira para moer folhas e grãos; uma mochila de pano para simular o modelo de mochila utilizada pelos idosos em seu contexto escolar; uma bola feita de tecido; um bilboquê, brinquedo de madeira o qual possui duas partes ligadas por um barbante que, ao serem arremessadas para o ar, se encaixam; e o mangual, que consiste em um objeto de madeira que era utilizado para "bater" nos grãos que ficavam em cima de um pano e assim descascá-los. Ao final das falas, os idosos confeccionavam um brinquedo com as crianças, o qual consistia em uma linha que transpassa um botão formando uma espécie de ioiô. O projeto é realizado pelo Conselho Municipal do Idoso desde 2013.

6 A pesquisa acompanhou cinco escolas, abrangendo um total de 179 crianças, de 8 a 10 anos de idade, que cursam o terceiro na do ensino fundamental da rede municipal de ensino. Das 5 escolas, 4 localizam-se no perímetro urbano e apenas 1 escola localiza-se na área rural. Das 179 crianças, 97 eram do sexo feminino e 83 do sexo masculino.

7 Idosos que conduzem o projeto "Idosos Mestres da Vida": eles têm idade de 73 e 71 anos, se autodeclaram brancos e são oriundos da área rural da cidade, além de aposentados, heterossexuais, casados, com filhos e, atualmente, residentes na área urbana. Ambos são conselheiros do Conselho Municipal do Idoso, sendo um deles presidente do respectivo Conselho. Outros idosos do Conselho foram convidados a participar do projeto, porém os únicos que efetivaram a participação foram os dois idosos que executaram o projeto no ano anterior, ou seja, os aqui referidos. No Conselho Municipal do Idoso de Concórdia, a maioria dos idosos participantes constitui-se de homens.

\section{Referências}

ANTUNES, Maria da Conceição Pinto; MOREIRA, Maria Cristina. Educação intergeracional e envelhecimento bem-sucedido. Revista Brasileira De Ciências Do Envelhecimento Humano, v. 15, n. 1, p. 21-32, jun. 2018.

ARENDT, Hannah. As origens do totalitarismo: Antissemitismo, Imperialismo, Totalitarismo. São Paulo: Companhia das Letras, 1989.

ARENDT, Hannah. Entre o passado e o futuro. São Paulo: Perspectiva, 2005.

ARENDT, Hannah. A Condição humana. Rio de Janeiro: Forense Universitária, 2010.

ARIÈS, Philippe. História social da criança e da família. Rio de Janeiro: LTC, 1981.

BARDIN, Laurence. Análise de Conteúdo. São Paulo: Edições 70, 2016.

BEAUVOIR, Simone de. A velhice. São Paulo: Nova Francesa, 1990.

BORGES, Carolina de Campos; MAGALHAES, Andrea Seixas. Laços intergeracionais no contexto contemporâneo. Estudos de Psicologia, Natal, v. 16, n. 2, p. 171-177, ago. 2011. 
BOSI, Ecléa. Memória e Sociedade: lembranças de velho. São Paulo: Companhia das Letras, 1994.

CESAR, Maria Rita de Assis; DUARTE, André. Hannah Arendt: pensar a crise da educação no mundo contemporâneo. Educação e Pesquisa, São Paulo, v. 36, n. 3, p. 823837, Dec. 2010. Disponível em: http://www.scielo.br/scielo.php?script=sci_arttext\&pi$\mathrm{d}=\mathrm{S} 1517-97022010000300012 \& \operatorname{lng}=\mathrm{en} \& \mathrm{nrm}=$ iso. Acesso em: 10 Oct. 2019.

CURY, Carlos Roberto Jamil. Direito à educação: direito à igualdade, direito à diferença. Cadernos de Pesquisa. São Paulo, n. 116, p. 245-262, jul. 2002.

DEBERT, Guita Grin. A antropologia e o estudo dos grupos e das categorias de idade. In: BARROS, Myriam Moraes Lins (org.). Velhice ou terceira idade? Estudos antropológicos sobre identidade, memória e política. Rio de Janeiro: Fundação Getúlio Vargas, p. 49-67, 1998.

DEBERT, Guita Grin. A dissolução da vida adulta e a juventude como valor. Horizontes antropológicos, Porto Alegre, v. 16, n. 34, p. 49-70, dez. 2010. Disponível em: http://www.scielo.br/ scielo.php?script. Acesso em: 10 nov. 2018.

GEERTZ, Clifford. A interpretação das culturas. [S.l.]: LTC, 1989.

GOLDFARB, Delia Catullo; LOPES, Ruth Gelehrter da Costa. Avosidade: A família e as gerações. In: FREITAS, Elizabete Viana de; PY, Ligia (org.) Tratado de Geriatria e Gerontologia. 4. ed. Rio de Janeiro: Guanabara Koogan, 2018. p. 2.182-2.193.

MAGNANI, José Guilherme Cantor. Etnografia como prática e experiência. Horizontes Antropológicos, Porto Alegre, ano 15, n. 32, p. 129-156, dez. 2009.

MESSY, Jack. A pessoa idosa não existe: uma abordagem psicanalítica da velhice. São Paulo: ALEPH, 1999.

MONTEIRO, Renata Alves de Paula; CASTRO, Lúcia Rabello de. A concepção de cidadania como conjunto de direitos e sua implicação para a cidadania de crianças e jovens. Revista Psicologia Política, v. 8, n. 16, p. 271-284, 2008.

OLIVEIRA, Paulo de Salles. Cultura e coeducação entre as gerações. Psicologia USP. São Paulo, v. 9, n. 2, p. 261-296, 1998.

OHLWEILER, Mariane Inês; FISCHER, Rosa Maria Bueno. Autoridade, infância e "crise na educação". Cadernos de Pesquisa, São Paulo, v. 43, n. 148, p. 220-239, abr. 2013.

SARMENTO, Manuel Jacinto. Infância, exclusão social e educação como utopia realizável. Educação e Sociedade, Campinas, v. 23, n. 78, p. 265-283, abr. 2002.

SARMENTO, Manuel Jacinto. As culturas da infância nas encruzilhadas da $2^{a}$ modernidade. In: SARMENTO, M. J.; CERISARA, A. B. (org.). Crianças e miúdos: perspectivas sócio pedagógicas da infância e educação. Porto: Asa, 2004, p. 9-34.

SARMENTO, Manuel Jacinto. Gerações e alteridade: interrogações a partir da sociologia da infância. Educação e Sociedade, Campinas, v. 26, n. 91, p. 361-378, ago. 2005.

SAWAIA, Bader Burihan. Cidadania, diversidade e comunidade: uma reflexão psicossocial. In: SPINK, M. J. P. A cidadania em construção: uma reflexão transdiciplinar. São Paulo: Cortez, 1994, p. 147-156. 
SILVA, Henrique Salzamo da; JUNQUEIRA, Patrícia Grandino. Reflexões e narrativas (auto) biográficas sobre as relações intergeracionais: resultados de uma intervenção socioeducativa com mulheres idosas. Psicologia e Sociedade, v. 25, n. 3, p. 559-570, 2013.

TOMÁS, Catarina. "Participação não tem idade": participação das crianças e cidadania da infância. Revista Contexto \& Educação, v. 22, n. 78, p. 45-68, maio 2013.

VEIGA, Marcia Regina Medeiros; FERREIRA, Sônia Cristina Mairos; CORDEIRO, Antônio Manuel Rochette. Construção de identidades(s) na velhice: os territórios enquanto marcos identitários. Psicologia e Sociedade, Belo Horizonte, v. 28, n. 3, p. 453-462, dez. 2016. 